\title{
Tills y otros depósitos relacionados con la dinámica glaciar en la Sierra do Xistral: interpretación de litofacies y reconstrucción paleoglaciar
}

Tills and related deposits linked to glacier dynamics in the Sierra do Xistral: interpretation of lithofacies and paleoglacier reconstruction

\author{
Marcos Valcárcel \\ marcos.valcarcel@usc.es \\ Departemento de Xeografía \\ Universidade de Santiago de Compostela (España)
}

\section{Resumen}

Los aparatos glaciares que se desarrollaron ella Sierra do Xistral originaron un modelado glaciar poco marcado, pero evidente. Se trata de un área montañosa de moderada altitud que soportó un campo de hielo (icecap) durante el Pleistoceno reciente. Se ha descrito la presencia de crestas morrénicas, planas fluvioglaciares, bloques erráticos y kames. La presencia de afloramientos en los que se puedan estudiar depósitos de origen glaciar es relativamente escasa, pero esto no impide que se presenten buenos ejemplos. En el presente trabajo se discuten tipos de tills, tanto subglaciares como supraglaciares así como depósitos fluvioglaciares y torrenciales. Su interpretación es un elemento importante a la hora de comprender la dinámica glaciar en este sector. El método de trabajo comprende una valoración visual de los distintos afloramientos y su integración en el contexto geomorfológico local. La posterior interpretación genética de los diferentes depósitos ha permitido precisar la dimensión de la glaciación en la Sierra do Xistral, aclarando qué áreas de valle quedaron ocupadas por los hielos glaciares y cuales se vieron libres de ellos. 
Palabras clave: till; fluvioglaciar; Serra do Xistral; NW Ibérico.

\begin{abstract}
The glaciers developed in the mountains of Sierra do Xistral shaped a glacial landscape, although not well defined. It is a low-lying mountain that was covered by an icecap during the Upper Pleistocene. The occurrence of moraine ridges, outwash plains, erratics and kames has been described. The places where deposits of glacial origin can be studied are relatively scarce, but this does not prevent good examples. Different types of till have been described, both sub-glacial and supraglacial, as well as fluvioglacial and torrential deposits. Their interpretation is an important element for understanding the glacial dynamics in this sector. This work is based on the usual method of work in this type of studies, which includes a visual analysis of the different sedimentary outcrops and their integration into the local geomorphological context. The genetic interpretation of the outcrops allows us to determine the extent of the glaciation in the Sierra do Xistral, determining which areas of the valley were occupied by the glacial ice and which were free of it.
\end{abstract}

Key words: till; fluvioglacial; Xistral mountains; NW Iberia.

\title{
1 Introducción
}

En la Sierra do Xistral, un núcleo montañoso de modestas altitudes enmarcado dentro del conjunto de las llamadas Serras Septentrionais gallegas, se han podido reconocer los vestigios de una importante actividad glaciar durante el Pleistoceno (Pérez Alberti et. al, 1993, 1995; Pérez Alberti \& Valcárcel, 1998; Valcárcel, 1998; Valcárcel 2001; Valcárcel et. al, 2012, 2015; Hall et. al, 2016). La presencia de crestas morrénicas, aunque relativamente abundante, no siempre señala el máximo avance de los hielo, por lo que la interpretación de los depósitos glacigénicos a nivel de afloramiento adquiere un importante valor a la hora de establecer una reconstrucción más precisa de la superficie ocupada por el hielo.

Los glaciares descritos en estos trabajos en el momento de máximo avance se identificaron como ejemplos de icecaps con prolongación en lenguas (Valcárcel, 1998). Se originaron a partir de la acumulación sobre las superficies de cumbres y el descenso de glaciares de escape que se canalizaron a través de los valles preglaciares de escasa pendiente. Las formas de erosión glaciar están poco desarrolladas y los circos glaciares son prácticamente inexistentes. La presencia de un icecap somital no propició su génesis. Los valles en U están también poco marcados. En muchos casos los hielos se limitaron a arrastrar los materiales preglaciares, acumulándolos en morrenas laterales o frontales, y en todo caso la evolución postglaciar tendió a mimetizar estas formas, originalmente poco marcadas. Se trata, pues, de un ámbito que sustentó un glaciarismo importante, 
pero cuyas huellas sobre el terreno son menos evidentes que en otros sectores del noroeste peninsular (Valcárcel, 1998).

Dadas estas circunstancias, se plantea el estudio sedimentológico de los afloramientos, con el objeto de reunir el mayor número de datos sobre el terreno, de manera que, contribuyendo a las conclusiones extraídas del estudio de las formas, se pueda deducir una interpretación de la génesis de los depósitos, y establecer la dimensión de la glaciación. Se ha abordado su descripción a partir de parámetros verificables visualmente y de su interpretación genética posterior, lo que ha permitido confirmar la presencia de depósitos de tipo till, tanto subglaciares de acreción o de fusión, como supraglaciares. Al mismo tiempo se han identificado diferentes depósitos de origen torrencial cuya filiación se vincula a la presencia de aguas de fusión glaciar. Así, en este estudio se presentan siete depósitos de origen glacigénico en la Sierra do Xistral, permitiendo reconstruir con mayor fiabilidad las dimensiones de la glaciación descrita en los trabajos previos.

Es generalmente aceptado que facies distintas en una misma secuencia sedimentaria se corresponden con contextos deposicionales diferentes, por lo que el estudio de los afloramientos debe proporcionar información muy valiosa sobre los ambientes en los que se acumularon los materiales y las interpretaciones genéticas de las facies sedimentarias permiten afrontar reconstrucciones paleoambientales locales más precisas. Por lo tanto, los depósitos glaciares pueden ser estudiados a nivel de afloramiento, analizando sus distintas facies, y pueden ser cartografiados como formaciones superficiales que son. Sin embargo, el estudio de los depósitos glaciares plantea problemas importantes tanto a nivel metodológico como incluso terminológico (Dreimanis, 1988). Siguiendo el método propuesto por Eyles et.al, (1983) se procedió a realizar una descripción sobre el terreno y posteriormente una intrepretación genética de las unidades deposicionales descritas en cada afloramiento. Establecida esta interpretación genética, la definición de las condiciones paleoambientales en las cuales se emplazó se deducen a partir del conocimiento de los mecanismos generales de deposición definidos para ese tipo de depósito, de manera que podemos relacionarlos con unas condiciones ambientales de deposición concretas (Boulton \& Eyles, 1979; Shaw, 1987; Lundqvist, 1988; Winkler \& Matthews, 2010, entre otros). Estas generalmente son conocidas a partir del análisis de procesos activos en la actualidad. Sin embargo, los depósitos de origen glaciar pueden estar sujetos a mecanismos de deposición complejos. Puede resultar difícil definir el proceso o el ambiente de deposición, y pueden estar sujetos a procesos de redeposición. Esta redeposición puede a su vez generar una interacción de distintos procesos en un mismo enclave a lo largo del tiempo o incluso coetáneamente, que puede dificultar aún más la interpretación.

Dada la referida complejidad terminológica en la que se inscribe el estudio de los depósitos glaciares, se adoptó una nomenclatura simple de las diferentes facies presentes en los depósitos. La planteada por Miall $(1977,1985)$ para los depósitos fluviales es el trabajo de referencia y ha sido 
adaptada con anterioridad al estudio de depósitos de origen glaciar por Eyles et. al, (1983) y Eyles \& Eyles, (1992). Estas clasificaciones descansan sobre criterios simples como granulometría, estructura y tipo de estratificación, reconocibles a nivel de afloramiento, de manera que las litofacies son puramente descriptivas y comparables con la descripción de depósitos activos, permitiendo establecer relaciones entre litofacies y dinámica sedimentaria. Por otra parte, como estos mismos autores afirman, diferentes facies pueden corresponder a una misma dinámica, en relación con variaciones laterales o longitudinales de la textura en el seno de una misma forma, en la medida en que la estratificación puede ser relativamente continua en una dirección y lenticular en la dirección perpendicular (Eyles et. al, 1983). Tal como señala Shaw (1987) una gran variedad de procesos sedimentarios tiene lugar en ambientes glaciales, resultando en secuencias sedimentarias generalmente complejas. La liberación de derrubios desde el hielo, el retrabajado y la deposición por los procesos de movimiento en masa, y la deposición en corrientes rápidas y/o en lagos pueden ocurrir dentro de unas pocas decenas de metros de un margen de hielo (Pérez Alberti et. al, 2011). A esta variabilidad espacial se añade la variabilidad temporal, con escalas diurnas, estacionales y otras de cambio en las condiciones climáticas que influyen en los procesos sedimentarios. Además de los continuos cambios en la posición de los márgenes del hielo, las corrientes de agua de fusión y los lagos marginales complican aún más la cuestión de las aguas de deshielo. De ello se deduce que las facies definidas específicamente dependen en gran medida del emplazamiento. Tales facies pueden ser o no útiles en otro sector de estudio. Los códigos de facies están diseñadas más para la interpretación de secciones transversales que para secuencias verticales (Shaw, 1987). A menudo los afloramientos de depósitos glaciares presentes en ambientes de glaciares de valle no tienen unas proporciones importantes o no son extensos, por lo que un estudio restringido a estos afloramientos puede resultar muy parcial e incompleto, e incluso imposible. En esta línea, de razonamiento Boulton y Eyles (1979, p. 11) señalan que las clasificaciones existentes "they do not distinguish between sediments and landforms deposited by valley glaciers and the very different sequences deposited by icecaps and ice sheets" por lo que "a genetic classification of the sediments and landforms produced by valley glaciers is suggested, which is bases primarily on the grain-size distinction betwen subgalglacially-derived and subglaciallyeroded debris, and secondly on the mode of deposition of that debris as till" (Boulton \& Eyles, 1979, p. 11). Establecen además una serie de criterios que permiten distinguir, desde un punto de vista genético, los materiales depositados por un glaciar de valle, y que son fácilmente aplicables en el campo. Es decir, lo que es una herramienta útil para la reconstrucción de grandes icecaps pleistocenos, donde el sedimento ha sido transportado a lo largo de centenares o miles de kilómetros, perdiendo contacto con las áreas fuente, puede ser útil también en ambientes confinados de valle, donde la procedencia del sedimento es mucho más cercana, pero donde la 
influencia de los procesos de ladera puede modificar, por procesos de resedimentación, la configuración final del sedimento.

Otros investigadores que trabajan en sectores cercanos dan, sin embargo, una gran importancia a la recolección de datos granulométricos o en el análisis de urdimbre (fabric análisis ${ }^{\top}$ ), con el objeto de completar la información adquirida por la interpretación visual (Santos Gonzalez, 2011; SantosGonzález et. al, 2013, 2015, 2017). En realidad todas estas técnicas requieren un importante trabajo sobre el terreno y en laboratorio y debe valorarse correctamente si realmente son útiles o aportan algo significativo al estudio e interpretación de los depósitos en cada caso. En ese sentido cabe destacar que un till es quizá el tipo de sedimento más variable conocido bajo un solo termino genético (Flint, 1971), ya que los glaciares tienen un comportamiento sedimentario distinto a otros tipos de ambientes. Presentan una competencia absoluta para trasportar sedimento, con independencia de su tamaño (Shaw, 1987). Además, reiteramos que cualquier material previo puede ser incorporado por el glaciar y ser re-sedimentado, conservando frecuentemente características de su ambiente deposicional anterior o heredado. Por otra parte, la litología, la textura, el tamaño de grano y la forma de los clastos están en gran medida controlados por el origen de los derrubios (Lundqvist, 1988; Winkler \& Matthews, 2010), y por tanto en los glaciares de montaña tiene un carácter local, al que es muy difícil aplicarle normas generales. Pero también es cierto que el transporte ejerce gran influencia en la forma de las partículas y en el tamaño de éstas. Se puede resumir esto citando a Benn y Evans (1998), que señalan que la estructura y características de los depósitos glaciares dependen básicamente de tres factores: El área fuente de los sedimentos, que controla la litología, y también puede ser importante para la morfología de la partícula y el tamaño del grano; el transporte del sedimento, que puede ser realizado por varios agentes, no sólo el hielo, desde su entrada en el sistema glaciar hasta su depósito final.; y por último los procesos deposicionales, que controla específicamente las propiedades sedimentarias. Además, sobre un depósito pueden actuar procesos postdeposicionales, especialmente importantes en el contexto de glaciares de valle. De esta manera, un análisis de urdimbre de un depósito puede revelar un origen no glaciar de un material sedimentario glacigénico, aunque los materiales procedan de un depósito glaciar que ha sido removilizado, caso evidente si estamos ante un

1 En inglés, el término "fabric" se refiere a la urdimbre de un tejido, evolucionando el término originalmente como un préstamo del francés medieval "fabrique", definido como "cosa hecha". De ahí derivó durante la revolución industrial de "material manufacturado" a "tela o tejido" dado que el inicio de la producción en factoría se centró, como es bien sabido, en la producción de textiles. Sin embargo en castellano "fábrica" viene directamente del término original latín faber, al igual que ocurría con el idioma francés, y significa artesano, haciendo referencia a un lugar en el que se realiza una actividad productiva o también a la construcción de un edifico, su estructura, pero preferentemente al lugar en el que se está erigiendo, sin ninguna relación con un material manufacturado o una tela. Por lo tanto la traducción literal "fabric" por "fábrica" es lo que se denomina en Lingüística un "falso amigo" y debe rechazarse, a pesar de lo extendido de su uso en la comunidad científica castellanohablante. Se propone el término "urdimbre", por ser el más cercano a su verdadero significado en lengua inglesa. 
proceso paraglaciar (Church \& Ryder, 1972). En ese caso un análisis de urdimbre o un análisis granulométrico pueden llegar a ser engañosos y carecer de valor diagnóstico.

Con estas premisas no siempre se cumple que los análisis exhaustivos relacionados con muestreo sobre el terreno y análisis de laboratorio tengan como objeto clarificar una interpretación genética, y no tanto aportar datos cuantitativos a los observacionales. Estos datos cualitativos deben ser igualmente interpretados y no aportan necesariamente un criterio discriminatorio, dado las características de deposición/redeposición que se dan en ambientes glaciares de valle. Son depósitos extremadamente heterogéneos y que difícilmente se pueden encuadrar en márgenes en los que estas técnicas tienen más sentido, como es el caso de los procesos deposicionales fluviales. En el presente estudio se plantea que un trabajo de identificación a nivel de afloramiento puede ser suficiente cuando estamos estudiando ambientes de valle en los que el confinamiento del glaciar facilita la interpretación a la luz del contexto geomorfológico.

\section{Métodos}

Se ha partido de la existencia de una cartografía geomorfológica previa realizada a partir de trabajo de campo iniciado en la primera mitad de los años noventa (Pérez-Alberti et. al, 1993, 1995; Valcárcel, 1998) y de nuevas aportaciones más recientes (Valcárcel et. al, 2015), y se ha completado esta cartografía geomorfológica de base mediante nuevos trabajos de campo, apoyándose en un Sistema de Información Geográfica (ArcGis 10.1). La utilización de datos LIDAR (Laser Imaging Detection and Ranging), ha permitido refinar los Modelos Digitales del Terreno (MDT), facilitando el cartografiado de las formas reconocidas en el trabajo de campo, en especial las crestas morrénicas de menor tamaño, como las descritas en el valle del Eume.

En cuanto a lo referido al análisis de los depósitos, se ha abordado la descripción de sedimentos glacigénicos a nivel de afloramiento, siguiendo el método expuesto en Valcárcel (1998) y trabajos previos similares en el ámbito del noroeste peninsular (Vidal Romaní et. al., 1990; Brum Ferreira et. al., 1992, 1999; Santos-González, 2011; Santos-González et. al, 2013, 2015, 2017). Dada la complejidad terminológica en la que se inscribe el estudio de los depósitos glaciares, se optó por utilizar una terminología simple para la descripción de las diferentes facies presentes en los siete afloramientos descritos. Esta se basa en la propuesta de Miall (1977) para el estudio de depósitos fluviales, adaptada por Eyles et. al, (1983) para el estudio de los depósitos de origen glaciar. Ésta clasificación descansa sobre criterios simples, expuestos en Vilaplana y Bordonau (1987), como son: la posición que ocupa el sedimento dentro del contexto geomorfológico local, su potencia vista, su estructura, ya sea maciza, estratificada etc, el tamaño de los clastos, su aspecto, así como su papel en la articulación de la estructura del depósito (clastosoportado colmatado o no, o bien matrizsoportado), el aspecto de la matriz (consolidado o no), y su grado de tenacidad (es decir, su resistencia a ser roto o disgregado). Todas estas características son reconocibles sobre el terreno. 


\section{3 Área de estudio}

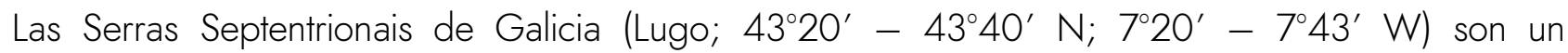
conjunto de montañas de fuerte horizontalidad culminante y marcada verticalidad en sus límites, que separa claramente el sector nororiental de la costa gallega y la depresión interior de origen tectónico de la Terra Chá (Figura 1). El núcleo central de estas sierras está formado por la Sierra do Xistral, que supera ligeramente los 1000 m s.n.m. (Seixo Branco 1057 m, Chao de Lamoso 1039 m, Xistral 1036 m) y los macizos graníticos de A Toxiza, con altitudes netamente inferiores (A Toxiza $838 \mathrm{~m})$.

Figura 1. Localización del área de estudio

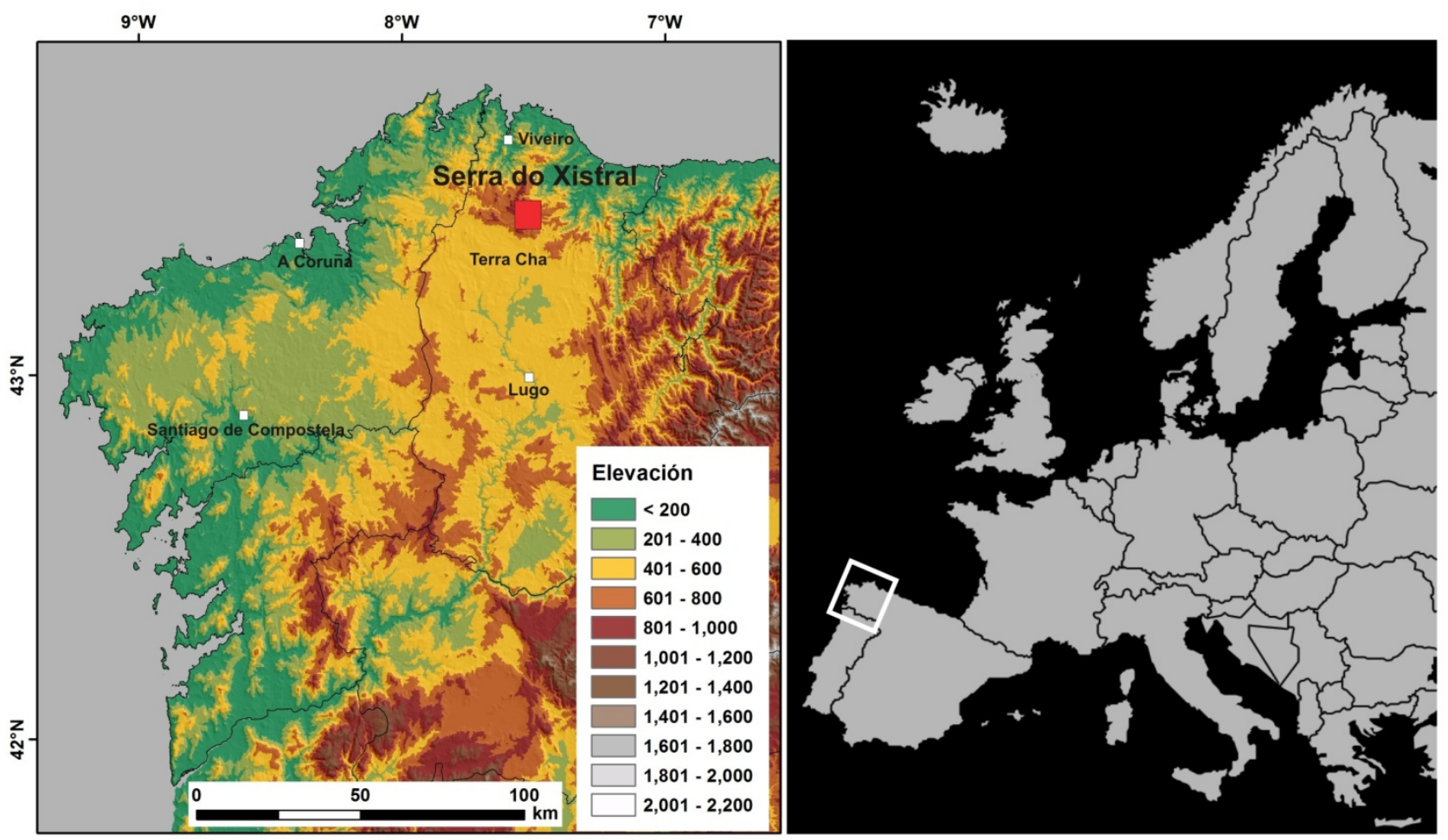

Fuente: elaboración propia

Climáticamente las zonas altas se caracterizan por una nubosidad muy regular a lo largo del año, dando lugar a una estacionalidad débil en la distribución de las precipitaciones y con un carácter marcadamente oceánico. La temperatura media anual oscila entre 7,5-10 ${ }^{\circ} \mathrm{C}$. La precipitación media anual varía entre los 1350 y 1700 mm (Martínez-Cortizas \& Pérez-Alberti, 1999). Especialmente durante el verano, estos relieves permiten que los flujos de procedencia oceánica generen entradas de aire superficial que consienten el desarrollo de nubes de estancamiento. Estas, junto con los fenómenos de nieblas de irradiación, colaboran de manera intensa en incrementar los aportes hídricos. Desde el punto de vista biogeográfico este territorio constituye el mejor exponente de los ambientes húmedo-frescos (Martínez-Cortizas \& Pérez-Alberti, 1999). 
En general el paisaje presenta un aspecto suave en el que predomina una vegetación de tipo arbustivo que pasa en las áreas más elevadas a extensas coberturas de turba de profundidades variables pero que frecuentemente supera los cuatro metros de profundidad (Pontevedra-Pombal et al., 2006). Estas peat bogs son de tipo ombrotrófico (Du Rietz, 1954), dentro de ellas del tipo "blanket bog" o de cobertor (Pontevedra-Pombal 1995) si nos referimos a las situadas en las áreas de divisoria de aguas, sobre las superficies aplanadas de cumbre, donde son ubicuas y prácticamente ocultan toda la superficie del substrato rocoso. También están presentes las turberas de tipo minerotrófico en las áreas bajas de drenaje dificultoso. Existen por ello muy pocas exposiciones de origen natural en las que se pueda estudiar el tipo de sedimentación ni el propio substrato rocoso. Este contexto, con una gran escasez de exposiciones del substrato y afloramientos de sedimentos, es el que dominó hasta finales de los años noventa. A partir de ese momento la construcción de una red viaria relacionada con la instalación de numerosos parques eólicos ha aumentado mucho el número de exposiciones, que si bien raramente son muy potentes o extensas, si son espacialmente abundantes.

Morfógicamente en la Sierra do Xistral podemos diferenciar un escalonamiento de distintas superficies aplanadas, fruto de la dislocación de una superficie fundamental y su basculamiento diferencial, presumiblemente durante diversas fases del Terciario. Estas superficies aparecen incididas por los valles que vierten directamente hacia el Cantábrico, debido a la cercanía de su nivel de base. Pero se da también la presencia de ciertos valles de pendiente mucho más suave en los tramos altos de los ríos, como son el Pedrido y el Eume. Estos tramos altos de suave pendiente fueron los más afectados por fenómenos glaciares durante el Pleistoceno, ya que en ellos los aparatos glaciares alcanzaron el fondo del valle, mientras en los otros casos los glaciares quedaron colgados sobre las laderas. Hemos relacionado estos trazados con fenómenos de captura fluvial que afectarían a ríos que drenaban sus aguas hacia la cuenca del Miño, y que sufrieron este proceso en un momento relativamente reciente, lo que ha permitido la conservación de la topografía original de estas cabeceras fluviales, mucho más suave que la del resto de los valles de la sierra, que tienen el nivel de base en el cercano mar Cantábrico (Valcárcel, 1998). De esta manera, observamos la combinación de superficies llanas bien desarrolladas en las áreas de cumbres y valles de pendiente muy suave en las áreas bajas, combinados con otros en los que la incisión ha sido mucho más intensa.

Desde el punto de vista geológico el área ocupada por la Sierra do Xistral, junto con los afloramientos graníticos los materiales que constituyen estas sierras pertenecen al Dominio del Manto de Mondoñedo y al de Navia y Alto Sil (Marcos, 1973; Martínez Catalán, 1985). Los materiales precámbricos se corresponden con una serie fundamentalmente esquistosa (Serie de Vilalba), que a través de una discordancia da paso a materiales paleozoicos como pizarras, esquistos y cuarcitas, estas últimas tableadas y en espesores muy poco potentes (Serie de 
Cándana). En la ventana tectónica de $\bigcirc$ Xistral también afloran rocas precámbricas muy migmatizadas e intruidas por un granito de dos micas. El Cámbrico inferior está formado por esquistos biotíticos y la "Cuarcita de $\bigcirc$ Xistral" (Parga Pondal \& Alexandre, 1966), que ocupa en la zona una gran extensión en una potente serie (Martínez Catalán, 1985) y se corresponde también con los sectores más elevados. Tenemos que poner de relieve que estas cuarcitas tienden a generar clastos de tamaño centimétrico pero no grandes bloques, muy raramente se acercan al metro. Por lo tanto va a ser muy difícil encontrar grandes bloques erráticos. Estos solo son posibles cuando afloran grandes diques de cuarzo que si son susceptibles de generar bloques métricos. Cuando encontremos grandes bloques erráticos será siempre de esta naturaleza. En el entorno del valle glaciar del Río Pedrido, su presencia es muy significativa. En cuanto a las rocas graníticas, destaca por su extensión la zona contigua del macizo granodiorítico de A Toxiza (Capdevilla \& Floor, 1970; Barrera et. al., 1982), pero que queda totalmente fuera del ámbito glaciado.

Los sectores estudiados en el presente trabajo se centran en el entorno del valle del Río Pedrido, en la cabecera del río Masma, y la cabecera del río Eume, en el sector conocido como "Mariñas do Rial".

\section{Resultados: estudio de los afloramientos}

Los nuevos trabajos de campo, así como el estudio de algunos nuevos afloramientos aparecidos con motivo de la construcción de infraestructuras relacionadas con la implantación de los mencionados parques eólicos, precisamente en las áreas más elevadas, han permitido poner de manifiesto que la dimensión de la glaciación, en cuanto a extensión de las masas de hielo, que fue mayor de lo descrito en estos trabajos previos.

\subsection{El valle de Pedrido}

En trabajos previos se ha descrito la existencia de actividad glaciar en este sector a partir de la presencia de formas de acumulación, que debido a sus características se han interpretado como crestas morrénicas. Así en Pérez-Alberti et. al, (1993, 1995), Valcárcel (1998) y más recientemente Valcárcel et. al, (2015), que amplia considerablemente el área ocupada por el glaciar, describen y cartografían varios conjuntos de morrenas (Figura 2). Una primera acumulación morrénica se emplaza a los $770 \mathrm{~m}$ de altitud, a los pies del pico Lombo Pequeno. Se trata de una cresta morrénica que obtura totalmente el valle, de manera que el río ha tenido que labrar su cauce en uno de los laterales. Esta forma de acumulación se enraíza en la ladera hasta alcanzar los $790 \mathrm{~m}$ (Figura 3A). El depósito se apoya sobre substrato gneísico (gneis amfibólico), pero está constituido por fragmentos casi en exclusiva de origen cuarcítico (Figura 3B). Esta morrena fue interpretada en su momento como el máximo avance glaciar (Pérez-Alberti et. al, 1993; 1995). Aguas arriba, en torno a los $880 \mathrm{~m}$ se encuentran dos crestas morrénicas frontolaterales. Se trata de dos formas 
imbricados, de unos $6 \mathrm{~m}$ de potencia máxima (Figura 3C y 3D). El escaso desnivel con respecto a las morrenas anteriormente citadas se traduce en un fuerte retroceso de la lengua de hielo, dada la escasa pendiente que presenta el fondo del valle. Se puede interpretar esta acumulación como un momento de estabilización del glaciar posterior, relativamente cercano, ya que el desnivel entre las dos formas es de menos de 100 m (Pérez Alberti et. al., 1993, 1995; Valcárcel, 1998).

\section{Figura 2. Esquema geomorfológico}

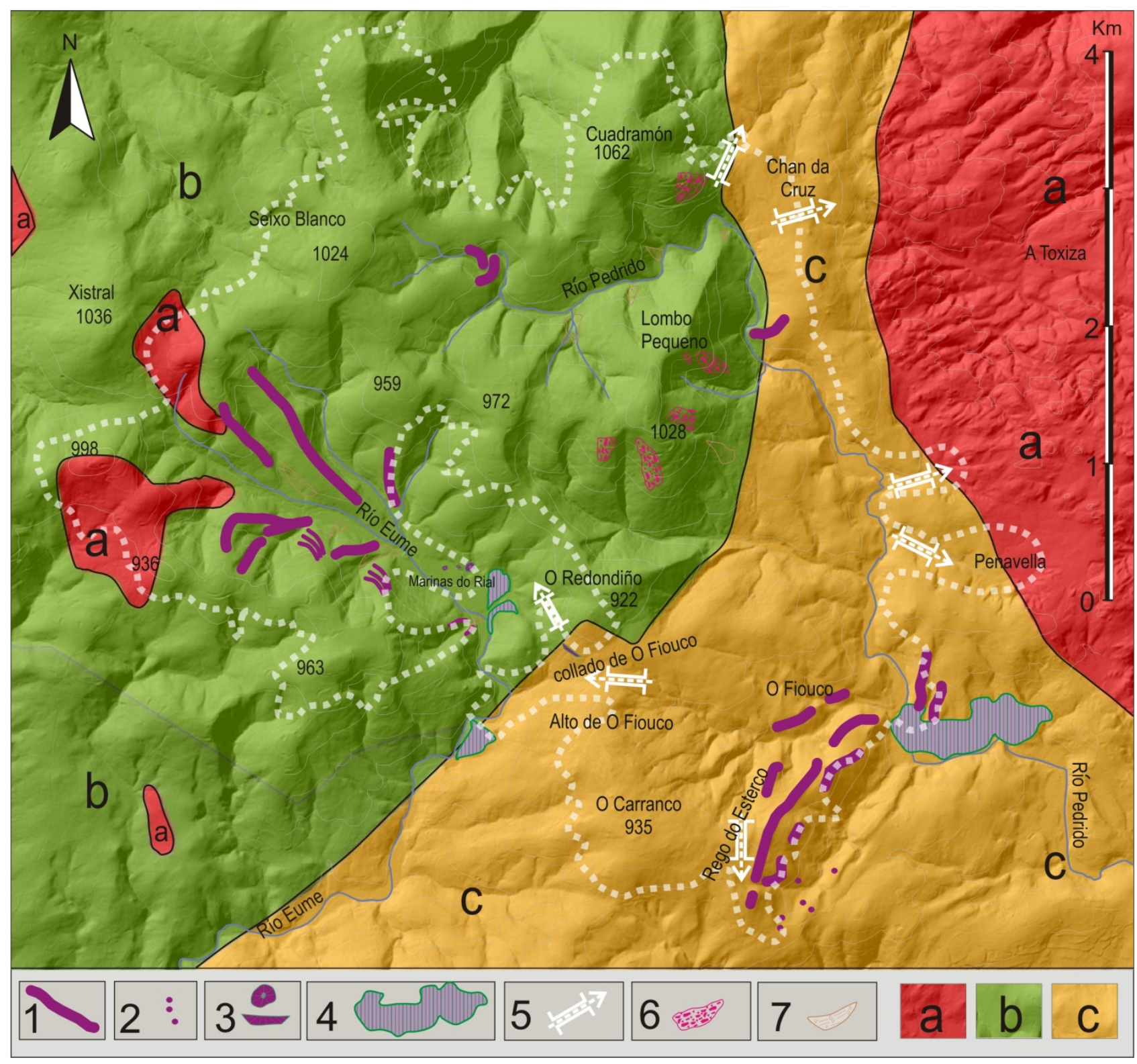

Leyenda: 1) Cresta morrénica; 2) Bloques erráticos; 3) Terrazas de kames y kettles; 4) Plana fluvioglaciar; 5) Collados de transfluencia; 6) Campos de bloques; 7) Conos fluviotorrenciales: a) Afloramientos de granito; b) Ortocuarcitas de Xistral; c) Series metamórficas: pizarras, gneis amfibólico. Con la línea discontinua se marca la extensión estimada del campo de hielo.

Fuente: elaboración propia 
Figura. 3. Complejos morrénicos en el tramo medio y superior del río Pedrido

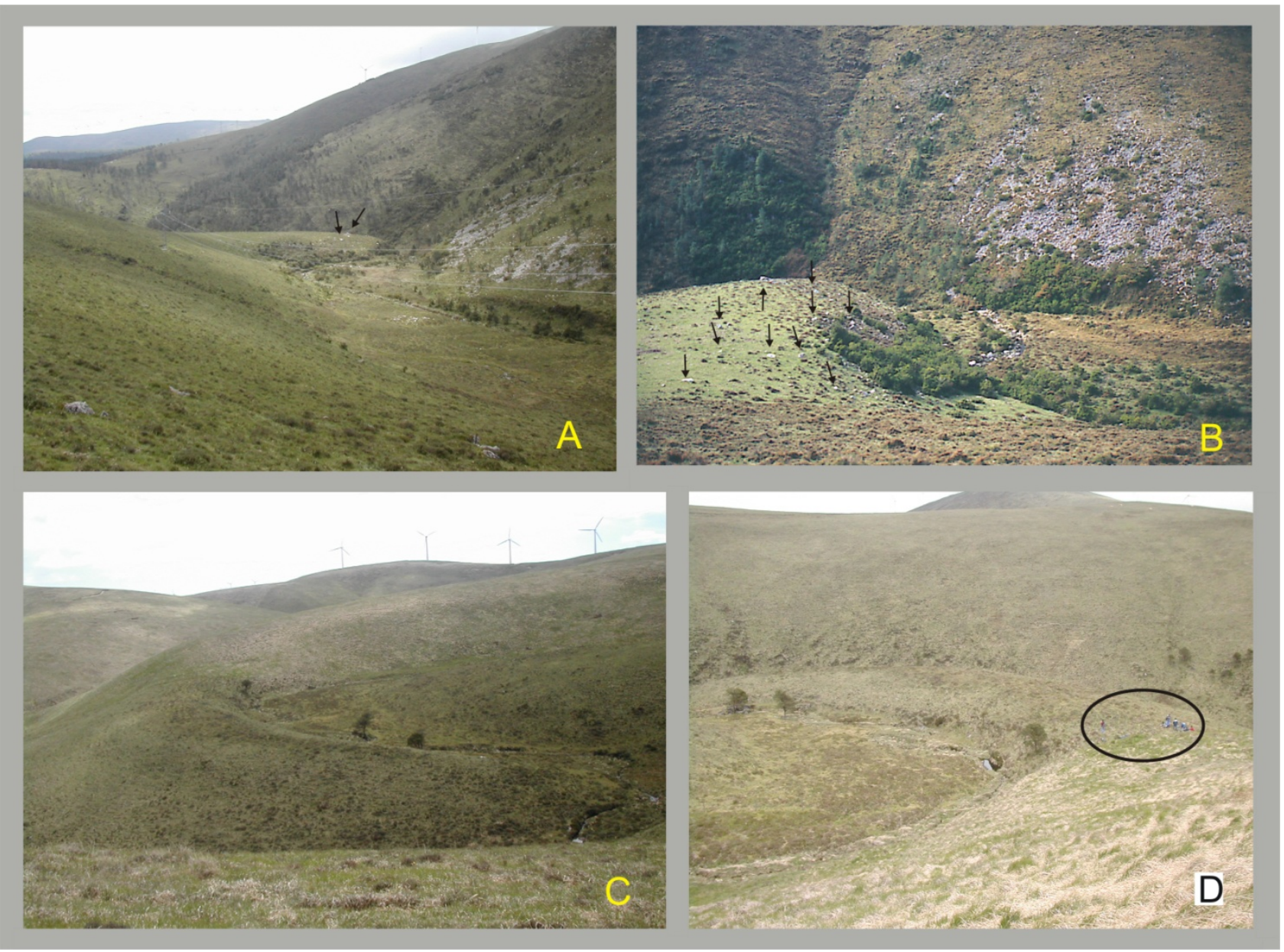

Leyenda: a) Se señalan con las flechas bloques erráticos de ortocuarcita. El substrato es metamórficos (gneis amfibólico), b) vista lateral del mismo aparato; c y d) dos vistas opuestas de la cresta morrénica situada en la cabecera del río Pedrido. En el círculo un grupo de personas da la escala de la estructura.

\section{Fuente: elaboración propia}

Sin embargo la interpretación de estas formas como indicadores del máximo avance del glaciar y de una fase de retroceso debe ser revisada a la luz de las nuevas observaciones, que en este valle han permitido comprobar que la extensión de la masa de hielo fue mucho mayor de lo descrito hasta ahora. Así, en este valle no existían afloramientos importantes hasta la construcción del vial que da paso a un parque eólico. Esto ha puesto de manifiesto la presencia de una potente cobertura de sedimentos de características glacigénicas que recubren la ladera que baja del pico Xistral (X-RP-1, Figura 4). A nivel de afloramiento podemos distinguir: 
Figura. 4. Emplazamiento y vista del depósito X-RP-1

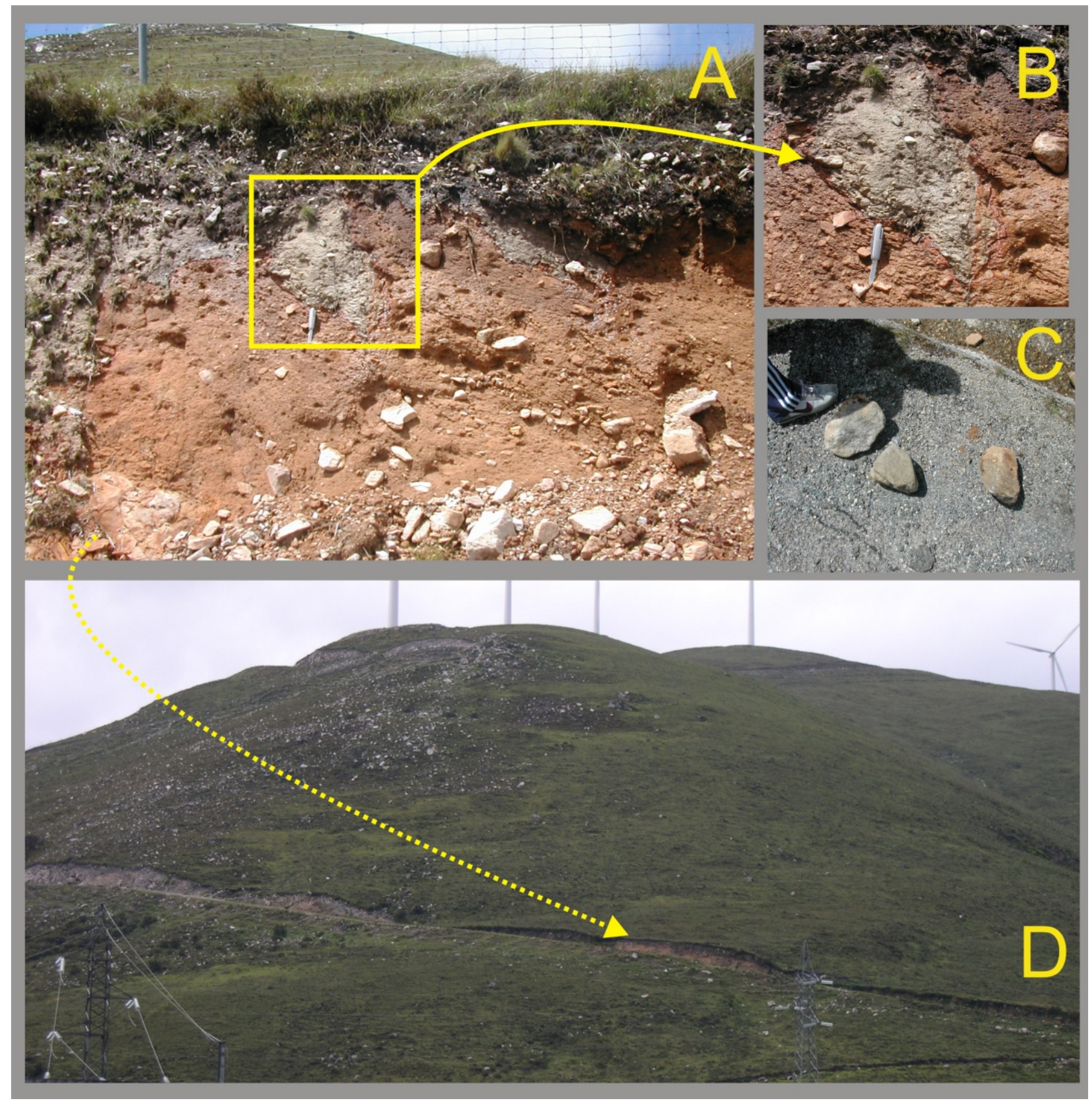

Leyenda: a) Vista general con el aspecto compacto y matrizsoportado del depósito. Se puede apreciar la pseudoestratificación; b) Un detalle del molde de cuña. Se trata de una estructura postdeposicional; c) Detalle del aspecto facetado y en forma de bala de los clastos de hielo; d) emplazamiento del depósito en la ladera, por encima del collado de difluencia.

Fuente: elaboración propia

Un diamicton matrixsupported massive (litofacies Dmm Eyles et. al, 1985), en el que los clastos presentan facetas y formas en plancha, así como frecuentes marcas de arrancamiento (Figura 4a, 4 b y 4c). El depósito presenta una urdimbre matrizsoportada en la que los clastos no se tocan entre sí, compuesta por un material limoarenoso de color amarillento y aspecto compacto y tenaz sin evidencias de resedimentación ni presencia de estructuras sedimentarias. Su parte superficial se ve 
afectada por indentaciones rellenas de sedimento de procedencia local con aspecto acuñado, limitadas en su contacto por una costra ferrujinosa compacta y dura, de unos cuantos milímetros de espesor (Figura 4b).

Genéticamente se interpreta como un lodgement till (Dreimanis, 1988). Las estructuras de acuñamiento de unos $30 \mathrm{~cm}$ de profundidad han sido interpretadas como ice wedge casts (Valcárcel et. al, 2015). Se trata en todo caso de estructuras posdeposicionales (Figura 4b).

La posición del depósito así como su morfología en superficie, con presencia de suaves crestas que se alinean hacia el collado (Figura 4d), indica que el glaciar llegó a fluir por lo menos hasta esta cota sobre el fondo del valle. Pero además, este volumen se hielo es coherente con la presencia de difluencias ya en este tramo superior del valle. En este sentido, un depósito de origen torrencial situado en la confluencia del pequeño arroyo que desciende desde Chan da Cruz hasta el río Furnas (deposito X-RF-1, Figura 2) debe ser indicador de una difluencia en el collado, que en todo caso no habría alcanzado el fondo del valle, pero sí podría haber generado aguas de fusión capaces de generar este yacimiento torrencial (Marínez de Pisón, comunicación personal).

\subsubsection{El depósito de Rego do Esterco}

Desde el pico de $\bigcirc$ Carranco $(935 \mathrm{~m})$ se configura una superficie alomada constituida por un afloramiento de gneises, y se extiende en dirección NW-SE. Presenta una disimetría de laderas evidente, siendo la que da al SW de formas convexas y suaves, mientras que la NE tiene pendientes más fuertes y una topografía cóncava y más compleja, con pequeños espolones suavizados que se prolongan hacia el fondo del valle. Uno de ellos, el más externo, de dirección SW-NE cierra este pequeño valle hasta conectar con el río Pedrido originando con este un estrechamiento. Sobre esta cresta, llamada Rego do Esterco, se asienta el conjunto de crestas morrénicas mejor desarrollado de todo el ámbito glaciar (Valcárcel et. al, 2015) (Figura 5a y 5b). Siguiendo la pista que rodea el cordal encontramos un pequeño afloramiento (X-RE-1, Figura 5e), el único en este sector. Se trata de una exposición de algo más de un metro de potencia en el que se distingue el substrato metamórfico sobre el que se aprecia un depósito, de algo más de $1 \mathrm{~m}$ de potencia, en contacto discordante con el propio substrato, y compuesto por clastos de uno a tres centímetro de tamaño de la misma litología que el substrato, con formas angulosas en el que se distinguen las siguientes unidades deposicionales: 


\section{Figura 5. Crestas morrénicas de Rego do Esterco y depósito X-RE-1}
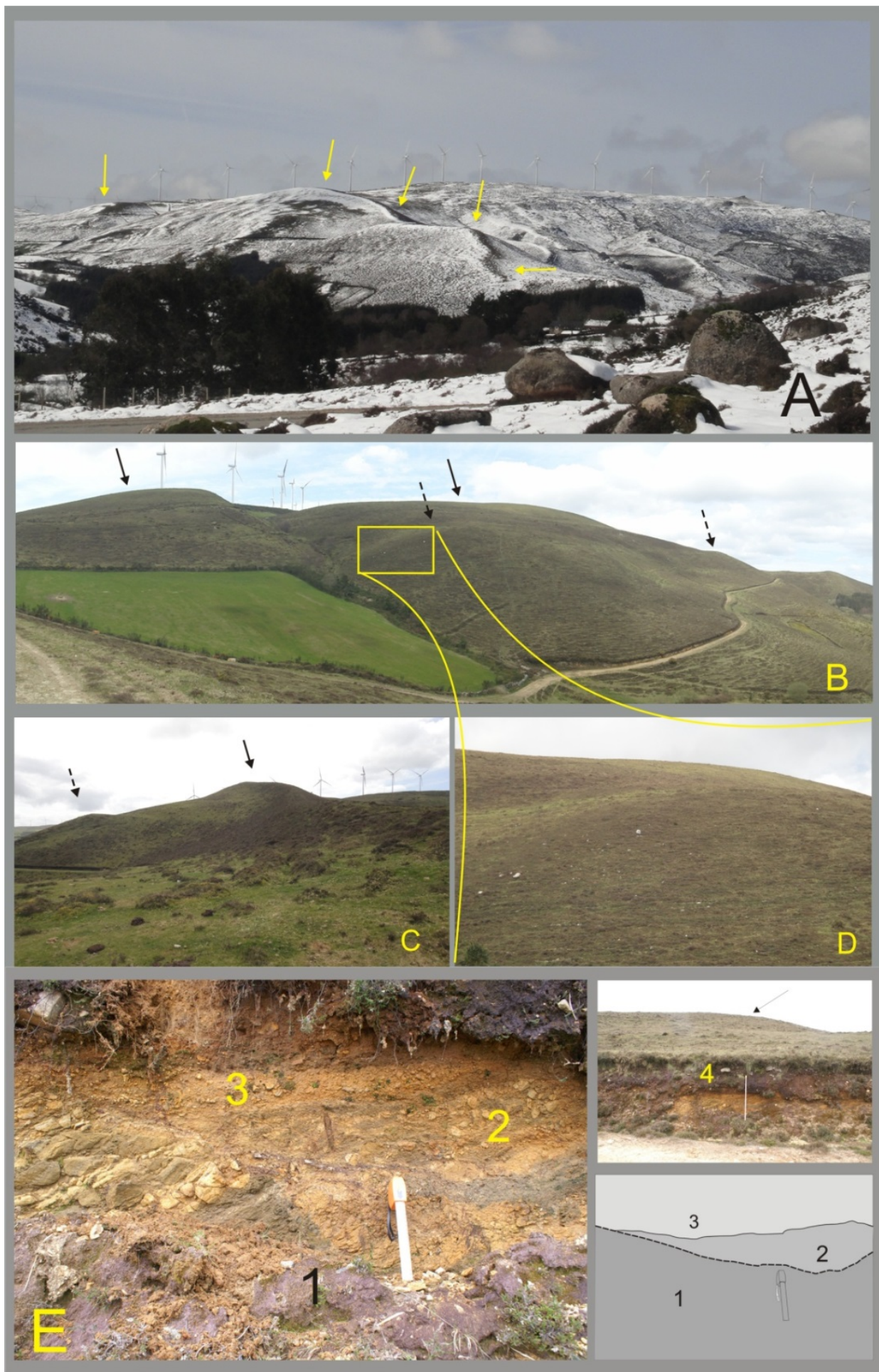

Leyenda: a) Vista de la cresta morrénica de Rego do Esterco; b) Se puede apreciar en la foto como la morena se desdobla en dos, lo que implica que el hielo desbordó este sector; c) vista de frente de las dos crestas morrénicas; d) Detalle de los bloques erráticos de ortocuarcita. En este sector el substrato es enteramente metamórfico, principalmente gneis amfibólico; e) Detalle del depósito X-RE-1: e1) Substrato metamórfico; e2) Till de deformación; e3) Till de acreción; e4) Till de fusión supraglaciar.

Fuente: elaboración propia 
Unidad inferior: Un primer nivel que se acuña desde un grosor de unos $20 \mathrm{~cm}$ hasta desaparecer hacia la derecha del depósito en contacto con el substrato no deformado, que presenta un aspecto brechoide, localmente con empaquetamientos de grabas clast supported embebidas en una matriz fina, de gran compacidad y tenacidad. Sobre él se distinque una capa de un grosor de unos $20 \mathrm{~cm}$ en los que se distingue un diamicton matrix suported massive (litofacies Dmm, Eyles et. al, 1982), compuesto por gravas angulosas de la misma litología del substrato (Figura 5e2).

Unidad superior: Sobre ellas se desarrolla un depósito de hasta $50 \mathrm{~cm}$ de potencia, compuesta por clastos de cuarcita de tamaño centimétrico y aspecto subredondeado que flotan en una matriz fina de color oscuro (litofacies Dmm) (Figura 5e3).

Desde el punto de vista genético podemos interpretar la unidad inferior como un deformation till (Dreimanis 1988) en el que el susbtrato ha sido arrancado in situ y con un transporte muy corto, de ahí que las gravas no hayan sido modeladas y presenten un aspecto anguloso. Por encima, la segunda unidad se corresponde con un material morrénico con cuarcita de origen alóctono (ortocuarcita) que puede ser directamente un supraglacial melt out till o incluso un flow till resedimentado a partir de un till supraglaciar, por procesos de solifluxión, ya que no hay estructuras que indiquen flujo de agua líquida (Figura 5e4). El color oscuro de la matriz se debe a la pigmentación por materia orgánica debido a la abundante presencia de histosoles, de los que esta materia orgánica es lixiviada con relativa facilidad debido a la textura poco compacta del de esta unidad inferior, mientras que la inferior, mucho más compacta, no es penetrada por esta.

Interpretación genética: El contexto indica la presencia de un till subglaciar sobre el que se ha depositado o redepositado un till supraglacial, por lo tanto primario o secundario (Dreimanis, 1988).

\subsection{El valle del Eume}

El valle del río Eume se sitúa al SW del valle del Pedrido, y también es un ejemplo de captura fluvial, ya que el valle presenta un perfil suave en sus primeros $3 \mathrm{~km}$ circulando en una dirección NNW-SSE, para cambiar bruscamente a una dirección NE-SE. Este cambio lo realiza atravesando una estrecha garganta que cierra la cabecera del valle del Eume, y siguiendo un trazado en bayoneta, indicador de un control de la red de fracturación. Esta disposición confiere a la Cabecera del Valle del Río Eume, conocido por el nombre de Mariñas do Rial, un aspecto confinado muy característico.

En trabajos previos se han descrito en este valle tanto formas de acumulación, crestas morrénicas, como afloramientos en los que se pueden observar depósitos glacigénicos, ya que hasta la proliferación de la instalación de parque eólicos, una de las pocas infraestructuras viarias que existían en Xistral era esta, que recorre el fondo del valle por su lado norte. En cuanto a las primeras, en la cartografía de Pérez Alberti et. al, (1993, 1995) ya se dibujaban dos alineaciones morrénicas que sugieren la ocupación del centro del valle por parte de una lengua glaciar, que 
llegaría a superar el tramo medio del valle. Su alimentación vendría dada principalmente por las superficies planas situadas al W y $S$ del valle, de las que descendería el hielo formando coalescencias o en algunos casos, pequeños aparatos colgados de la pared, y que tuvieron una dinámica muy pulsante, como se puede deducir de la presencia de gran número de pequeños arcos morrénicos progresivamente retranqueados hacia estas cabeceras (Hall et. al, 2016). La mejora en la resolución de los Modelos Digitales del Terreno (MDT) a partir de datos LIDAR, que han abierto la posibilidad de elaboración de una cartografía topográfica con una resolución de un metro, ha permitido trabajar con mucho mayor detalle y realizar una cartografía más precisa (Figura $6)$.

\section{Figura 6. Morrenas de retroceso en el valle del Eume}

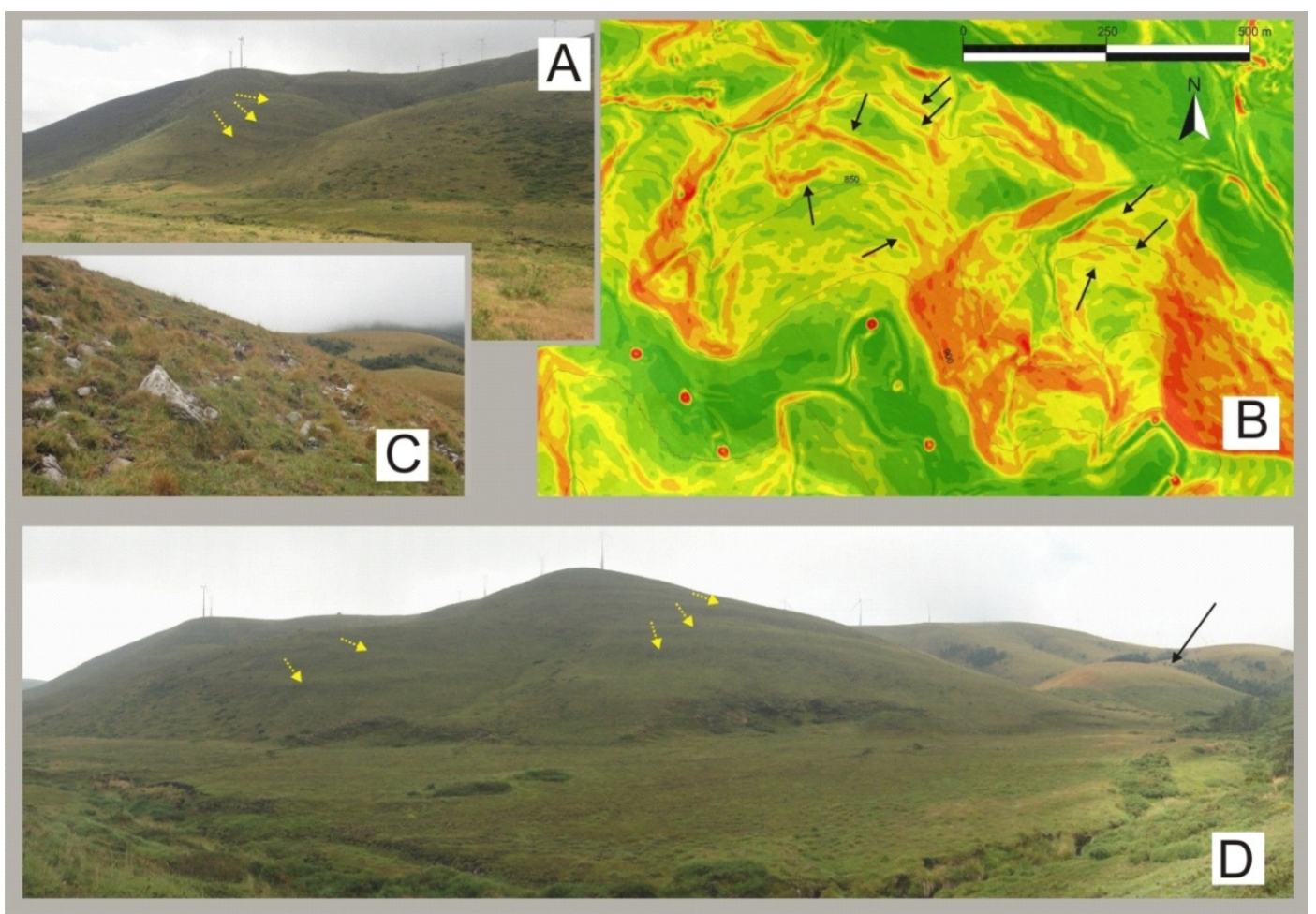

Leyenda: Morrenas de retroceso en el valle del Eume. A y D, dos vistas de las crestas, poco marcadas sobre el relieve. B modelo de orientaciones elaborado a partir de un Modelo Digital del Terreno de $1 \mathrm{~m}$ de resolución (datos LIDAR, los círculos rojos son aerogeneradores del parque eólico).Con el mapa de orientaciones se perciben mejor las pequeñas morrenas de retroceso, dada su escasa altura. En D las flechas claras indican las diferentes crestas morrénicas que señalan un retroceso del glaciar ladera arriba, mientras que la flecha negra indica un aparato morrénico mayor, en posición lateral al valle principal. En C se puede observar un detalle del aspecto de estas, conformadas por sedimentos con predominio de macroclastos de ortocuarcita.

\section{Fuente: elaboración propia}

Los depósitos que afloran con motivo de la construcción de la carretera presentan, evidentemente, una total uniformidad litológica, ya que todo este sector está dominado por las ortocuarcitas, salvo pequeños afloramientos de rocas graníticas en las cercanías del pico Xistal (X-E-1a. Figura 7): 


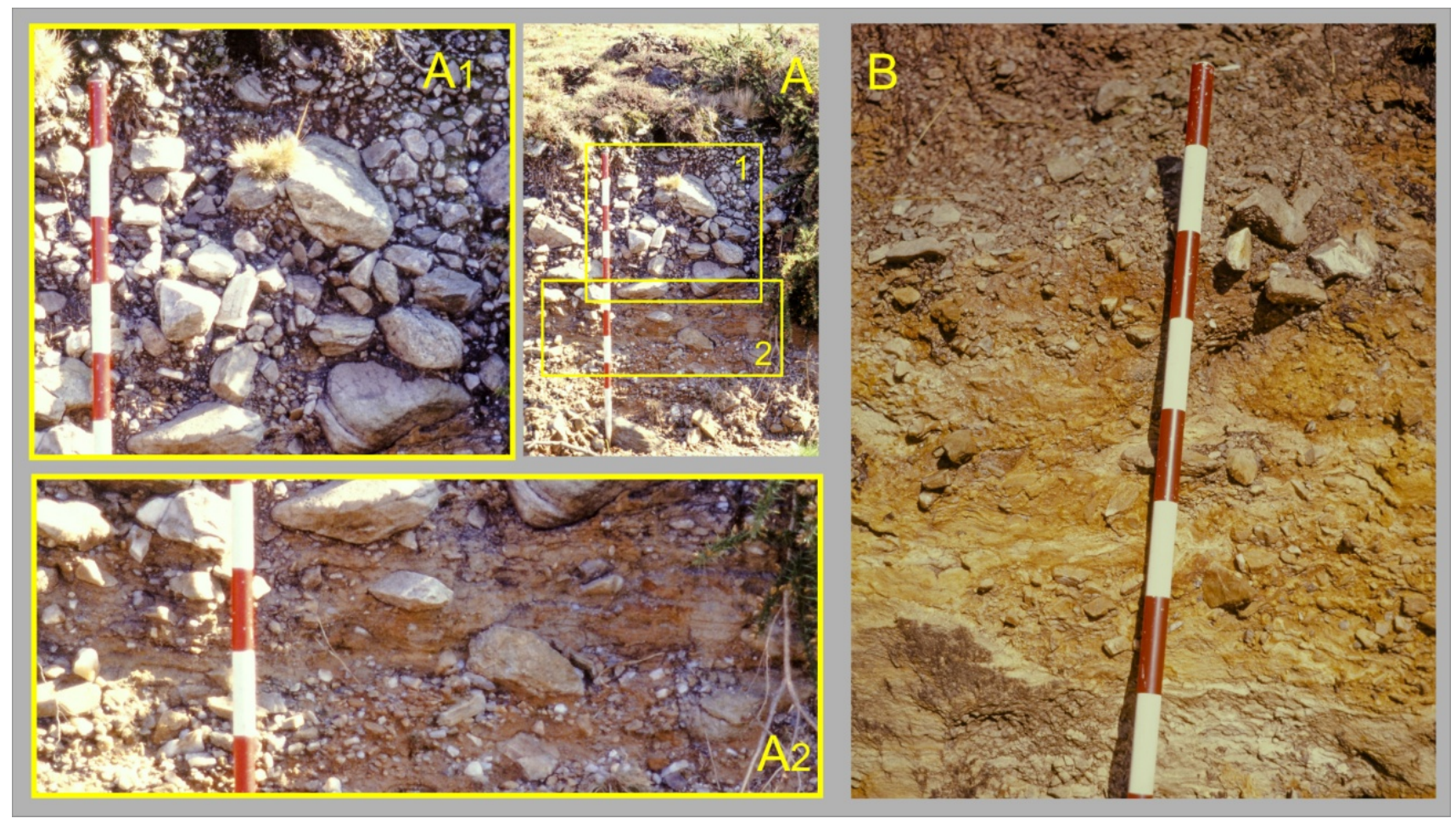

Leyenda: a1) till de fusión supraglaciar. Urdimbre clastosoportada colmatada. Predominan los clastos subangulosos con facetas y frecuentes arrancamientos; a2) Detalle de la unidad inferior. Un till de acreción con su típico aspecto compacto y pseudoestratificado. Los clastos flotan en la matriz; b) Detalle de la unidad inferior del depósito X-E-1b. Se trata de un till de acreción.

\section{Fuente: elaboración propia}

Unidad inferior: Presenta una potencia vista de $40 \mathrm{~cm}$, y está compuesto por un diamictón matrizsoportado macizo (Dmm) muy compactado, en el que los clastos, de naturaleza exclusivamente cuarcitosa, están englobados en una matriz limoarcillosa de color amarillento, presentando una cierta pseudo esquistosidad. Los clastos tienen formas subangulosas y un tamaño de 5-10 cm de eje mayor. El contacto con la unidad superior es gradual (Figura 7a2 y 7b).

Unidad superior: Presenta una potencia vista de 50-60 cm. Está compuesta por un diamictón clastosoportado macizo (Dcm), en el que los clastos, también exclusivamente cuarcitosos y están englobados en una matriz limoarcillosa poco compactada. Presentan formas de subangulosas a subredondeadas, variando su tamaño entre 5 y $30 \mathrm{~cm}$ de eje mayor. Presentan facetas y localmente se acumulan en paquetes.

Interpretación genética:

El depósito responde a la sucesión típica de un till de acreción (lodgement till; Dreimanis, 1988) sobre el que descansa un till de fusión supraglaciar (supraglacial melt out till; Dreimanis, 1988). 
A nivel de afloramiento el depósito X-E-1b señala el máximo avance del glaciar en este sector (Figura 8). Lateralmente el depósito continúa, variando en su estructura interna.

Figura 8. Vista lateral y detalles del depósito X-E-1b

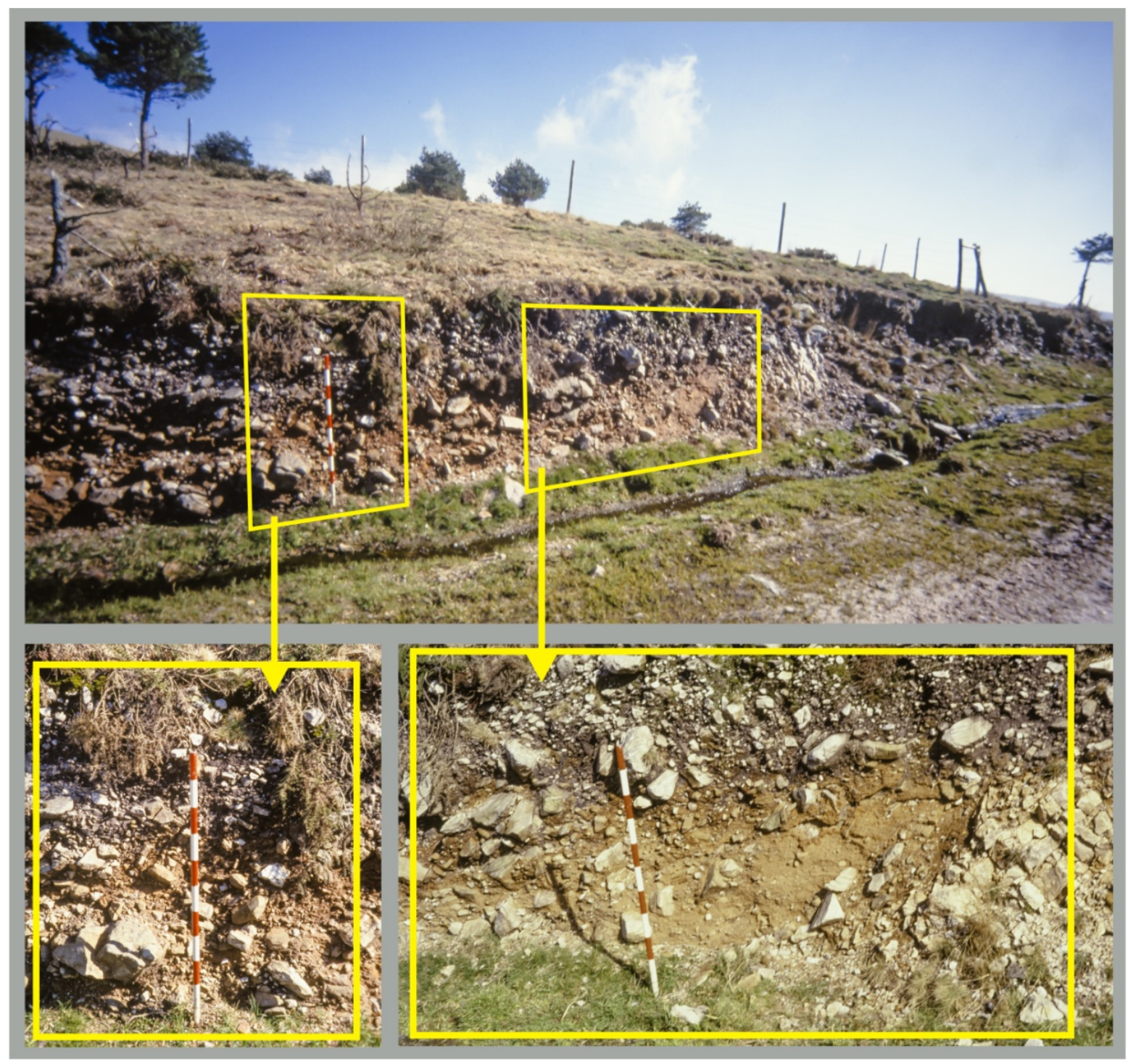

Fuente: elaboración propia

Presenta una potencia vista de $120 \mathrm{~cm}$, en dos unidades deposicionales:

Unidad inferior: Es una unidad deposicional, compuesta por un diamictón matrizsoportado macizo (Dmm) en el que los clastos cuarcitosos, subangulosos, flotan en una matriz limoarenosa compactada y dura de color amarillento, y es muy heterométrico, ya que el tamaño de grano varía entre 3-5 cm y $30 \mathrm{~cm}$ de eje mayor. El sedimento aparece alojado y encajado en la roca del substrato del cual algunos clastos han sido arrancados e incorporados al sedimento.

Unidad superior: Hasta $80 \mathrm{~cm}$ de un deposito clastosoportado macizo, muy heterométrico que presenta clastos con caras facetadas y aspecto subanguloso, La matriz es limoarenosa y presenta una menor compactación que la unidad inferior y un cambio de color hacia tonos más ocre 
Interpretación genética:

El depósito se corresponde con las características de un till de deformación; sobre él se depositaría un till de fusión subglaciar (Dreimanis, 1988). El depósito X-E-1a-b presenta una sucesión típica de materiales depositados en ambiente subglaciar, con indicación del avance glaciar en este sector.

Continuando por la pista forestal, unos metros más adelante, encontramos otro depósito en el que vuelven a presentarse facies de deposición diferenciadas:

Unidad inferior: Hasta $30 \mathrm{~cm}$ de un diamictón matrizsoportado macizo (Dmm) en el que los clastos cuarcitosos y cuarcíticos, de aspecto subanguloso a subredondeado, flotan en una matriz limoarcillosa muy dura. El tamaño de grano es muy pequeño $(1-3 \mathrm{~cm}$ de eje mayor, pudiendo alcanzar los $10 \mathrm{~cm}$ hacia el techo de la unidad. Presenta un aspecto de pseudo esquistosidad típico. El contacto con la unidad superior es neto.

Unidad superior: Presenta hasta $1 \mathrm{~m}$ de potencia vista. Está compuesta por un diamictón clastosoportado macizo (Dcm), en el que los clastos angulosos o subangulosos, flotan en una matriz limoarenosa poco compactada. El tamaño de grano es mayor, oscilando entre 3 y $10 \mathrm{~cm}$ de eje mayor, alcanzando frecuentemente los $15-20 \mathrm{~cm}$.

Interpretación genética:

La unidad inferior se corresponde con un till de acreción (lodgement till; Dreimanis, 1988), que representa el avance de una lengua de hielo en este sector. La unidad superior se corresponde con un till de fusión supraglaciar (supraglacial melt-out till; Dreimanis, 1988). Este último representa el retroceso del glaciar en un único evento, por lo menos en este sector.

En conjunto el estudio de los afloramientos nos informa de la presencia de una pequeña lengua glaciar que avanzó sobre el fondo del valle del Eume y retrocedió en un único evento glaciar detectable. Estos depósitos indican que el glaciar debió progresar claramente hasta el tramo medio del valle y acercarse a su tramo final, pero no permiten asegurar que llegó a ocupar todo el valle, alcanzando una cota de 640 m, aunque no se puede descartar que descendiese más.

Por otra parte en el tramo final del valle, apoyado sobre una ladera de la cota $838 \mathrm{~m}$, la apertura de una pequeña cantera permite observar el relleno hasta el nivel del substrato rocoso. Se trata de un afloramiento que está cortando los depósitos adosados a la ladera, ya que están unos 5 m por encima del relleno actual del valle. En este afloramiento se puede distinguir cómo el depósito se apoya directamente sobre el substrato rocoso (X-E-3, Figura 9): 
Figura 9. Depósito X-E-3 emplazado en tramo final de la cabecera del Valle del río Eume

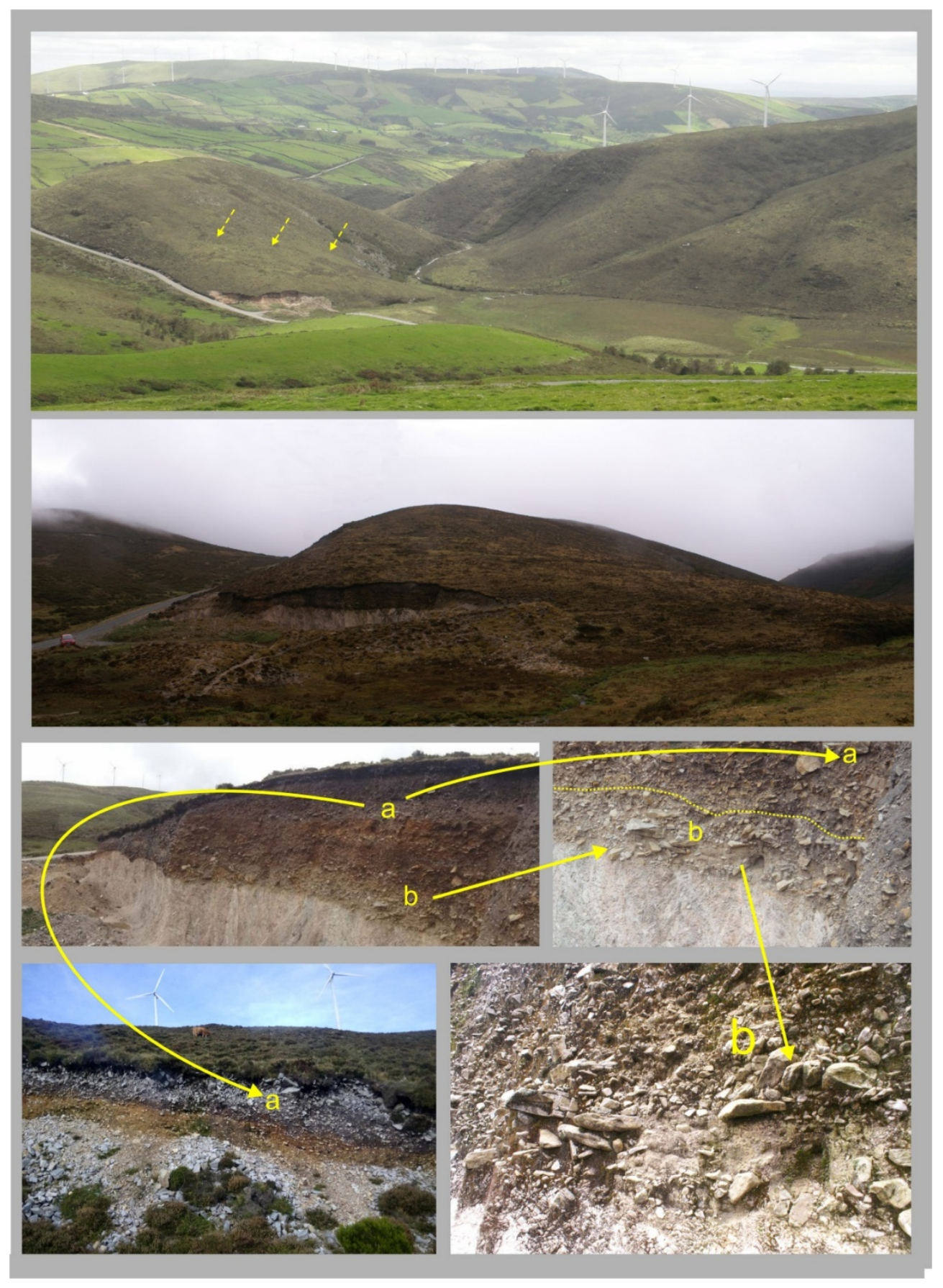

Fuente: elaboración propia

Se trata de una forma adosada al pico Redondiño. Las flechas en la imagen superior permiten señalar la ruptura de pendiente. Por lo tanto, los depósitos de ladera que tapizan todo el pico Redondiño están apoyándose en una forma previa que se prolonga con una topografía plana al otro lado del cauce abierto por el arroyo. El afloramiento permite ver que el deposito superior, un depósito de ladera periglaciar tipo head (Figura 9a), no descansa directamente sobre el substrato, sino que se apoya sobe un depósito de más de 1,5 m de espesor compuesto por clastos subredondeados (Figura 9b) con muestras evidentes de transporte en un ambiente fluido. 
Unidad inferior: en la que son abundantes los clastos de subredondeados a redondeados, de gran tamaño, embebidos en una matriz limoarenosa. Por su litofacies el depósito ha sido transportado en un contexto fluido, y no pudo ser aportado desde la ladera en la que se apoya, dado su escaso desarrollo. El depósito que lo fosiliza si se corresponde con un depósito de ladera, un "head", un término introducido por De la Beche (1839) para describir un "rubble drift" no clasificado y no consolidado. Se trata, pues, de un depósito de ladera de origen periglaciar donde los cantos son angulosos de tamaño centimétrico, aunque más pequeños que los del depósito inferior. Una vista lateral permite observar como este depósito se apoya sobre el inferior originando una ruptura de pendiente en la ladera. Esta forma se conecta con la contigua al otro lado del arroyo, siendo en realidad la misma estructura que ha sido cortada por la incisión torrencial que baja por la ladera SSW del Pico Redondiñao (922 m). El origen de la unidad inferior puede ser tanto un aporte de sedimentos transportados en un contexto fluvioglaciar proximal, con dominio de torrencialidad, incluso debris flow, pero en todo caso ser derivado de un derrame procedente de una pequeña lengua que atravesaría el pequeño collado superior. Tendría que derivar de hielo que procediese del vecino valle de Pedrido, por transfluencia a través de collado situado entre el Alto do Fiouco (918 m) y el pico $\bigcirc$ Redondiña (922 m). Este hielo difluente pudo alcanzar la cabecera del Eume por este paso.

Esta interpretación viene reforzada por la presencia un afloramiento emplazado a $810 \mathrm{~m}$ de altitud sobre la ladera $S$ que baja del pico Redondiño. Se trata de un afloramiento de una decena de metro de longitud y unos $2,5 \mathrm{~m}$ de potencia vista, generado con las labores de apertura del vial que comunica a los parques eólicos con una subestación eléctrica. En él podemos observar (X-E-4, Figura 10):

Figura 10. Deposito X-E-4

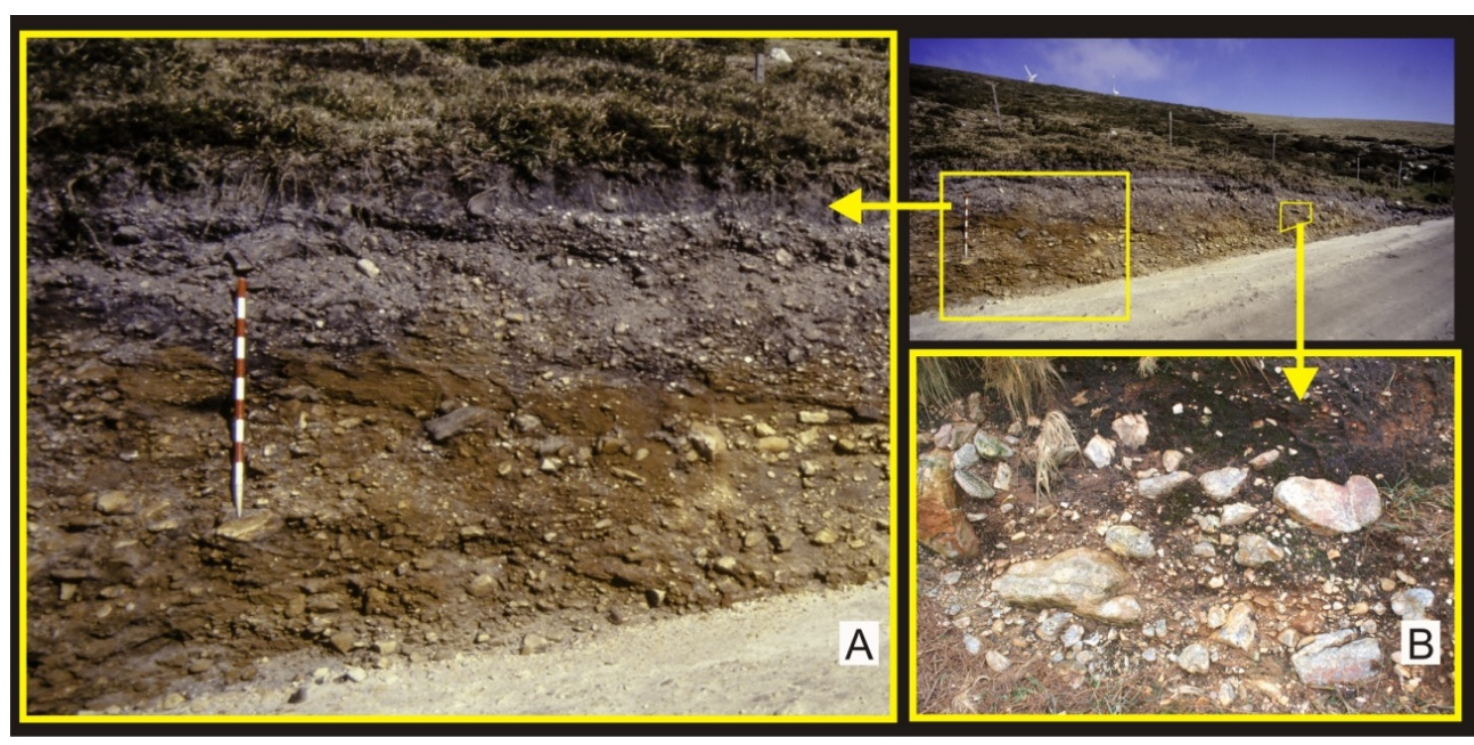

Fuente: elaboración propia 
Unidad inferior: compuesta por clastos de cuarcita que frecuentemente superan los $20 \mathrm{~cm}$ de eje mayor, de aspecto ligeramente subedondeado a anguloso, embebidos en una matriz limoarenosa, también de naturaleza cuarcítica (Figura 10a y 10b). En ella los clastos aparecen orientados en posición paralela a la pendiente indicando una dirección de flujo E-W y se observan empaquetamientos con imbricaciones que indican un flujo paralelo a la pendiente.

Unidad superior: Sobre ella y en contacto discordante se presenta un depósito compuesto por clastos de cuarcita de menor tamaño, angulosos, embebidos en una matriz arenolimosa.

Interpretación genética: El depósito debe tener un origen torrencial y se corresponde con un flujo de agua que circuló paralelamente a las curvas de nivel sobre una ladera que actualmente presenta una pendiente de unos $25^{\circ}$. Los materiales de la unidad superior son claramente un depósito de ladera de origen periglaciar, tipo "head", sobre los que se acumulan unos $20 \mathrm{~cm}$ de turba, que origina una coloración oscura de este depósito por infiltración de la materia orgánica.

Una explicación razonable es que se dio en este sector una corriente yuxtaglaciar que desmanteló materiales de ladera o del propio glaciar depositándolos sobre la ladera. Posteriormente la evolución de la ladera fosilizaría el depósito inferior en un ambiente periglaciar con aporte de sedimentos de origen local (redeposición).

\section{Discusión}

Las evidencias encontradas en la sierra do Xistral permiten sostener fehacientemente la instalación de masas glaciares sobre estas montañas, a partir del estudio de las formas y depósitos. La dimensión de la glaciación no debe, sin embargo, enmascarar que la disposición del relieve preglaciar debió jugar un papel muy importante en el control de las dimensiones de los diferentes aparatos glaciares. En primer lugar la presencia de extensas superficies de marcada horizontalidad en toda la montaña, longitudinalmente extensas, pero estrechas trasversalmente, y con una cota media cercana a los 850-900 m de altitud, lo que supuso la existencia de una superficie de captación de nieve excelente pero limitada. Fueron estas superficies las que alimentaron los principales aparatos. Es de hecho una cierta disimetría entre la disponibilidad de superficies por encima de los 850 m metros de altitud la que puede explicar razonablemente porqué el glaciar del Pedrido fue más potente y extenso que el glaciar del Eume, con menor superficie de captación, por lo que no pudo rellenar completamente el valle, quedando su frente presumiblemente en el tramo final del valle. En segundo lugar, estos icecaps debieron ser relativamente delgados, por lo que su acción de desmantelamiento y desgaste fue muy limitada. Este mismo fenómeno es aducido por Evans et. al. (2012) para justificar el escaso modelado de erosión glaciar de las montañas Darmort (suroeste de Inglaterra). La dificultad añadida para la observación sobre el terreno que supone la extensa cobertura de diferentes tipos de turberas, tanto en las áreas elevadas como en las bajas, y 
que enmascara totalmente el substrato, es un factor a tener en cuenta, a la hora de valorar correctamente el efecto del glaciar sobre las superficies rocosas. De ahí la conveniencia de completar la información con el estudio de los afloramientos. En todo caso, la mayor acumulación se dio en el fondo de los valles, donde el desnivel entre las cotas alcanzadas por el hielo indica un espesor, para el Valle del Pedrido, de más de 100 m de hielo. Es evidente que el glaciar debió difluir por diferentes collados, y que esto limitó también su potencia en su tramo final. De no ser así su espesor hubiese sido incluso mayor. La distancia desde la cabecera del río es de unos 7 km, lo que implica duplicar la longitud señalada en los trabajos anteriores (Pérez Alberti et. al, 1993, 1995; Valcárcel, 1998).

En la misma línea, el hecho de que el hielo glaciar del río Pedrido llegara a alcanzar la cota señalada por el depósito X-RP-1 supone que prácticamente se duplica potencia de hielo estimada en estos estudios (Pérez Alberti et. al, 1993, 1995; Valcárcel, 1998). Esto justificaría la presencia del depósito X-RF-1. Además, implica que en la parte media del valle tuvo que presentar difluencias glaciares, ya en el sector de Chan da Cruz, pero sobre todo en los dos collados siguientes, concretamente en el situado que da paso a Penavella. Este sector está ocupado por un extensa y profunda turbera minerotrófica, ubicada en un alveolo alterado sobre sustrato de granito (Pontevedra-Pombal et. al, 2006). Clastos subangulares de ortocuarcita aparecen esporádicamente sobre este sustrato granítico, lo que indica la presencia de esa difluencia de hielo. En cualquier caso, cualquier evidencia sedimentológica más consistente puede estar enterrada bajo la gruesa capa de turba.

Sobre la vertiente que une el Pedrido con el valle del río Eume se dio otra difluencia, ya que su máxima altitud señalada por las morrenas de Rego do Esterco se sitúa 50 m por encima de la altura alcanzada por el collado. Esta difluencia explicaría la presencia de restos de una outwash plain en el valle del Eume. De la misma manera se explica la presencia del depósito X-E-3. El agua de fusión yuxtaglaciar depositaría una terraza de kame de la que quedan solo retazos. Sin embargo no hay evidencias, por el contrario, de que el hielo procedente de la cabecera del Eume y esta difluencia llegase a fusionarse a través del collado, donde el depósito situado en la parte baja sería un pequeño cono fluvioglaciar. Tampoco hay evidencias de un aporte de hielo glaciar desde la estrecha garganta por la que circula el río en este sector En todo caso debió quedar cerrada por el hielo que descendía desde el collado y que alcanzó un pequeño resalte rocoso situado al W de los Altos do Fiouco, sobre la que se generó una la llana proglaciar o "outwash plain" antes citada, y de la cual solo queda la parte adosada a la ladera E. A la largo de la ladera E es posible localizar clastos de cuarcita apoyados sobre un substrato de gneis amfibólico. Esto necesariamente originó la obturación del tramo final de la cabecera del valle del Eume y la formación de un lago proglaciar. Actualmente esta superficie se encuentra totalmente cubierta por depósitos de turba. 


\section{Conclusiones}

El estudio a nivel de afloramiento de los depósitos glacigénicos se ha revelado como una herramienta válida para completar la reconstrucción de las masas glaciares en la Sierra de o Xistal. La conjunción de la información proporcionada por el estudio de estos afloramientos, junto con la elaboración de una cartografía geomorfológica, permite abordar una mejor reconstrucción de la dimensión del fenómeno glaciar en estas montañas, así como una mejor interpretación de su dinámica.

El análisis de los depósitos permite corroborar que se trata de sedimentos de origen glaciar. Su asociación con las formas de acumulación y si integración en la interpretación geomorfológica nos permite confirmar la presencia de un icecap, con prolongación en lenguas de escape. Se ha identificado también la presencia de difluencias en diferentes tramos del valle del río Pedrido, pero sin poder verificar una conjunción con la lengua glaciar que se canalizó por el valle del Eume.

El tipo de sucesión característico es la presencia de un till subglaciar (lodgment till o deformation till) en contacto erosivo con el substrato, sucedido por la presencia de un till supraglaciar (supraglacial melt out till). Alternativamente puede aparecer este último únicamente. En general los depósitos aparecen fosilizados por depósitos de ladera de origen periglaciar, o acumulados por procesos paraglaciares, aunque el material supraglaciar aflora frecuentemente en superficie, sobre todo asociado a acumulaciones morrénicas. También se han descrito depósitos fluvioglaciares o fluviotorrenciales asociados a posiciones proximales del frente del glaciar. En general la interpretación de la sucesión sedimentológica solo permite hablar de un único evento de avance y retroceso.

En su conjunto la reinterpretación del glaciarismo de la Sierra de o Xistal, a la luz de los datos aportados por el estudio de los afloramientos, nos permite confirmar que este fue más extenso que lo descrito en los trabajos publicados en los años noventa del siglo pasado. Por un lado el glaciar del valle del Pedrido alcanzó cotas mucho más bajas. Por otro, el glaciar del valle del Eume no parece haber desbordado el espacio confinado de su cabecera, o por lo memos esto no se puede afirmar a partir del estudio de los depósitos.

Agradecimientos: El autor quiere agradecer a Ramón Blanco Chao su colaboración en el trabajo de campo y a Carlos Valcárcel Gay su ayuda en la edición y digitalización de parte de las imágenes utilizadas en el presente trabajo.

Declaración responsable: El autor declara que no existe ningún conflicto de interés en relación a la publicación de este artículo. Este trabajo fue parcialmente financiado mediante la ayuda de Consolidación e Estructuración 2017 GRC Gl-1667-RODA, ED431C 2017/26. Xunta de Galicia, España. 


\section{Bibliografía}

Barrera, J. L., Bellido Mulas, F., Maciá, P., \& Arps, C. E. (1982). Evolución petrológico geoquímica de los granitoides hercínicos del NO gallego. Cadernos do Laboratorio Xeolóxico de Laxe: Revista de xeoloxía galega e do hercínico peninsular, 3, 21-52.

Benn, D.I., \& Evans, D. J. A. (1998). Glaciers and glaciations. London:, Arnold.

Boulton, G. S., \& Eyles, N. (1979). Sedimentation by valley glaciers: a model and genetic classification. Moraines and varves, 33, 11-23.

Brum Ferreira, A., Vidal Romaní, J. R., Vilapalna, J. M.; Rodrigues, M. L., Zêzere, J. L., \& Monge, C. (1992). Formas e depósitos glaciarios e periglaciarios da serra do Gerês-Xures (Portugal; Galicia). Levantamiento cartográfico. Cuadernos do Laboratorio Xeolóxico de Laxe, 17, 121-135.

Brum Ferreira, A., Vidal Romani, J., Zêzere, J., \& Rodrigues, M. (1999). A Glaciação Plistocénica da Serra do Gerês: vestígios geomorfológicos e sedimentológicos. Centro de Estudos Geográficos, Relatório, 37, 1-150.

Capdevila, R., \& Floor, P. (1970). Les différents types de granites hercyniens et leur distribution dans le nord ouest de I'Espagne. Boletín Geológico y Minero, LXXXI.-II-III, 215-225.

Church M., \& Ryder J. M. (1972). Paraglacial sedimentation: A consideration of fluvial processes conditioned by glaciation. Geological Society of America Bulletin, 83, 3059-3072.

De la Beche, H. T. (1839). Report on the geology of Cornwall, Devon and West Somerset. London: Her Majesty's Stationery Office.

Dreimanis, A. (1988). Tills: their genetic terminology and classification. In R. P. Goldthwait \& C. L. Matsch (Eds.), Genetic classification of glacigenic deposits (pp. 17-83). Roterdam: A.A. Balkema.

Du Rietz, G. E. (1954). Die Mineralbodenwasserzeigergrenze als Grundlage einer natülichen Zweigliederung der nord-und mitteleuropäischen Moore. Vegetatio, 5(1), 571-585.

Evans, D. J., Harrison, S., Vieli, A., \& Anderson, E. (2012). The glaciation of Dartmoor: the southernmost independent Pleistocene ice cap in the British Isles. Quaternary Science Reviews, 45, 31-53. http://dx.doi.org/10.1016/j.quascirev.2012.04.019

Eyles, N., \& Eyles, C. H. (1992). Glacial depositional systems. In Facies Models: Response to Sea Level Changes (pp. 73-100). Geological Association of Canada.

Eyles, N., Eyles, C. H., \& Miall, A. D. (1983). Lithofacies types and vertical profile models; an alternative approach to the description and environmental interpretation of glacial diamict and diamictite sequences. Sedimentology, 30(3), 393-410.

Flint, R. F. (1971). Glacial and Quaternary Geology. New York: John Wiley \& Sons 
Hall-Riaza, J. F., Valcárcel, M., \& Blanco-Chao, R. (2016). Caracterización morfométrica de formas glaciares en cuña en las Sierras de Xistral, Teleno y Cabrera. Polígonos. Revista de Geografía, 28, 55-71. http://dx.doi.org/10.18002/pol

Lundqvist, J. (1988). Glacigenic processes, deposits and landforms. In R. P. Goldthwait \& C. L. Matsch (Eds.), Genetic classification of glacigenic deposits (pp. 3-16). Rotterdam: A.A. Balkema.

Marcos, A. (1973). Las series del Paleozoico Inferior y la estructura herciniana del Occidente de Asturias (NW. de España). Trabajos de Geología, 6(6), 3-113.

Martínez Catalán, J. R. M. (1985). Estratigrafia y estructura del Domo de Lugo (Sector Oeste de la Zona Asturoccidental-leonesa). Fundación Pedro Barrie de la Maza, Conde Fenosa.

Martínez-Cortizas, A., \& Pérez-Alberti, A. (1999). Atlas climático de Galicia. Xunta de Galicia.

Miall, AD. (1977). Lithofacies Types and Vertical Profile Models in Braided River Deposits: A Summary. In A.D. Miall (Ed.), Fluvial sedimentology (pp. 597-604). Canadian Society of petroleum Geologists. Calgary mem.

Miall, A. D. (1985). Architectural-element analysis: a new method of facies analysis applied to fluvial deposits. Earth-Science Reviews, 22(4), 261-308.

Parga Pondal, I., \& Aleixander, T. (1966). La arenisca ortocuarcítica del Gistral, Lugo. Not. y Com. Instituto de Geología y Minería de España, 87, 59-90.

Pérez-Alberti, A., Rodríguez-Guitián, M., \& Valcárcel, M. (1993). Las formas y depósitos glaciares en las Sierras Orientales y Septentrionales de Galicia (NW Península Ibérica). In La evolución del paisaje en las Montañas del entorno de los Caminos Jacobeos (pp. 61-90). Santiago de Compostela: Xunta de Galicia.

Pérez-Alberti, A., Rodríguez-Guitián, M., \& Valcárcel, M. (1995). Acción e importancia del frío durante el Cuaternario reciente en las Sierras Septentrionales de Galicia (Noroeste Ibérico). In Actas de la $3^{a}$ Reuniâo do Quaternário Ibérico (pp. 79-84). Coimbra, September 27-October 1.

Pérez-Alberti, A., \& Valcárcel, M. (1998). Caracterización y distribución espacial del glaciarismo en el Noroeste de la Península Ibérica. In Las huellas glaciares de las montañas españolas (pp. 1762). Santiago de Compostela: Universidade de Santiago de Compostela.

Pérez-Alberti, A., Valcarcel, M., Martini, I. P., Pascucci, V., \& Andreucci, S. (2011). Upper Pleistocene glacial valley-junction sediments at Pias, Trevinca Mountains, NW Spain. Geological Society, 354(1), 93-110. http://dx.doi.org/10.1144/SP354.6 0305-8719/11

Pontevedra-Pombal, X. (1995). Histosoles de la Serra dos Ancares (Galicia) (MA Thesis, Universidad de Santiago de Compostela, Spain). 
Pontevedra-Pombal, X., Muñoz, J. N., García-Rodeja, E., \& Cortizas, A. M. (2006). Mountain mires from Galicia (NW Spain). Developments in Earth Surface Processes, 9, 85109. https://doi.org/10.1016/s0928-2025/06)0

Pontevedra-Pombal, X., García-Rodeja, E., Valcárcel, M., Blanco-Chao, R., \& Costa-Casais, M. (2015). Las turberas de las Sierras Septentrionales de Galicia: Un patrimonio Europeo Singular. In A. Hilario, M. Monge Ganuzas, F. Fernández, J. Vegas \& A. Belmonte (Eds.), Patrimonio geológico y geoparques, avances de un camino para todos (pp. 119-124). Madrid: Instituto Geológico y Minero de España.

Santos-González, J. (2011). Glaciarismo y periglaciarismo en el Alto Sil, provincia de León (Cordillera Cantábrica) (Doctoral dissertation, Universidad de León, Spain).

Santos-González, J., Santos, J. A., González-Gutiérrez, R. B., Redondo-Vega, J. M., \& GómezVillar, A. (2013). Till fabric and grain-size analysis of glacial sequences in the Upper Sil River Basin, Cantabrian Mountains, NW Spain. Physical Geography, 34(6), 471490. https://doi.org/10.1080/02723646.2013.855989

Santos, J. A. B., Santos-González, J., \& Redondo-Vega, J. M. (2015). Till-Fabric analysis and origin of late Quaternary moraines in the Serra da Peneda Mountains, NW Portugal. Physical Geography, 36(1), 1-18. https://doi.org/10.1080/02723646.2014.961218

Santos, J. A. B., Santos-González, J., Redondo-Vega, J. M., \& Irwin, J. R. (2017). Glacial deposits in the Serra do Gerês Mountains (NW Iberian Peninsula): till macrofabric analysis. Physical Geography, 38(3), 263-285. https://doi.org/10.1080/02723646.2016.1276879

Shaw, J. (1987). Glacial sedimentary processes and environmental reconstruction based on lithofacies. Sedimentology, 34(1), 103-116.

Valcárcel, M. (1998). Evolución geomorfológica y dinámica de las vertientes en el NE de Galicia. Importancia de los procesos de origen frío en un sector de las montañas lucenses (Doctoral dissertation, Universidade de Santiago de Compostela, Spain).

Valcárcel. M. (2001). Una forma glaciar erosiva (Breitböden) como indicadora del régimen térmico de dos glaciares Pleistocenos en la Sierra de Xistral (NW Ibérico). In Actas del XVII Congreso de Geógrafos Españoles (pp. 230-232). Madrid: Asociación de Geógrafos Españoles y Universidad de Oviedo.

Valcárcel, M., Carrera-Gómez, P., \& Blanco-Chao, R. (2012). Una forma glaciar erosiva como indicadora de condiciones paleoambientales durante el pleistoceno reciente en el NW de la Península Ibérica. In Avances de la geomorfología en España 2010-2012 (pp. 661-664). Sociedad Española de Geomorfología (SEG). 
Valcárcel, M., Pontevedra-Pombal, X., Sampedro, J.R., García-Rodeja, E., Blanco-Chao, R., \& Costa-Casais, M. (2015). Las turberas de las Sierras Septentrionales de Galicia: Un patrimonio Europeo Singular. In A. Hilario, M. Monge Ganuzas, F. Fernández, J. Vegas \& A. Belmonte (Eds.), Patrimonio geológico y geoparques, avances de un camino para todos (pp. 137-142). Madrid: Instituto Geológico y Minero de España.

Vilaplana, J. M., \& Bordonau, J. (1987). Los tills subglaciares del Pirineo: Criterios de identificación. In Actas de la VII Reunión sobre el Cuaternario (pp. 197-199). Santander (Cantabria): AEQUA. https://doi.org/10.1016/j.geomorph.2009.10.011

Vidal-Romani, Jr., Vilaplana, J. M., de Brum Ferreira, A., Zezere, J. L., Rodrigues, L., \& Monge, C. (1990). Los tills de la Serra de Gerês-Xurés y la glaciación pleistocena (Minho, Portugal-Ourense, Galicia). Cuaternario y Geomorfología, 4, 13-25.

Winkler, S., \& Matthews, J. A. (2010). Observations on terminal moraine-ridge formation during recent advances of southern Norwegian glaciers. Geomorphology, 116(1), 87-106. 